\title{
(息)
}

Citation:

Tate, S and Page, D (2018) Whiteliness and institutional racism: Hiding behind (un)conscious bias. Ethics and Education, 13 (1). pp. 141-155. ISSN 1744-9642 DOI: https://doi.org/10.1080/17449642.2018.1428718

Link to Leeds Beckett Repository record:

https://eprints.leedsbeckett.ac.uk/id/eprint/4621/

Document Version:

Article (Accepted Version)

This is an Accepted Manuscript of an article published by Taylor \& Francis in Ethics and Education on 1 Feb 2018, available online: http://www.tandfonline.com/10.1080/17449642.2018.1428718

The aim of the Leeds Beckett Repository is to provide open access to our research, as required by funder policies and permitted by publishers and copyright law.

The Leeds Beckett repository holds a wide range of publications, each of which has been checked for copyright and the relevant embargo period has been applied by the Research Services team.

We operate on a standard take-down policy. If you are the author or publisher of an output and you would like it removed from the repository, please contact us and we will investigate on a case-by-case basis.

Each thesis in the repository has been cleared where necessary by the author for third party copyright. If you would like a thesis to be removed from the repository or believe there is an issue with copyright, please contact us on openaccess@leedsbeckett.ac.uk and we will investigate on a case-by-case basis. 


\section{Whiteliness and institutional racism: Hiding behind (un)conscious bias}

\section{Abstract}

'Unconscious bias happens by our brains making incredibly quick judgements and assessments of people and situations without us realising. Our biases are influenced by our background, cultural environment and personal experiences. We may not even be aware of these views and opinions, or be aware of their full impact and implications' (ECU, 2017). This article speaks against this point of view by arguing that bias is not unconscious but is instead (un)conscious and linked to Charles Mills' (1997:40) 'Racial Contract' and its 'epistemologies of ignorance'. These epistemologies of ignorance emerge from what the Equality Challenge Unit (ECU) calls 'our background, cultural environment and personal experience' (ibid). As such, asserting that racism stems from 'unconscious bias' diminishes white supremacy and maintains white innocence as a 'will to forget' institutional racism. In equality and diversity training 'unconscious bias' has become a performative act to move beyond a racialized reality to where 'we all know better' because we have been trained to participate in a constructed 'post-racial' (Goldberg, 2015) reality. The article argues that it is through decolonizing 'unconscious bias', 'white fragility' and 'self-forgiveness' that we can begin to see hidden institutional whiteliness at the base of (un)conscious bias.

\section{Key words}

Unconscious bias, epistemologies of ignorance, decolonizing, 'post-racial', equality, diversity, racism, white fragility

\section{Introduction}

'Unconscious bias' has ceased to be just a phrase, a gesture towards so-called 'unwitting racism' and a call to anti-racist forgiveness of individual and institutional racism. 'Unconscious bias' has become ever more prevalent within institutions, transmogrified into corporate training as an essential accoutrement to an organization's equality and diversity mission and 
institutional anti-racist transformation at the levels of culture, process and systems. With roots in social psychology (see for example Dovidio et al, 1997), unconscious bias has become the magic bullet for organizations, including universities, in the face of the continued occurrence of racism. Despite protestations of egalitarianism and meritocracy, UK universities remain largely white institutions with the rarity of senior academics of colour rivalling the corporate sector. Such is the cognitive dissonance between racism and egalitarianism, universities - like their corporate counterparts - have sought a means of addressing whiteliness that avoids an acknowledgement of structural and systemic racism. Thus, unconscious bias has emerged within the equality, diversity and inclusion environment in UK Higher Education Institutions (HEls) as an explanation for statistical racial disparities. Unconscious bias is the acceptable face of racism, the phrase that a majority white sector feels comfortable with using and discussing to describe itself. Unconscious bias is neatly addressed by a ten-minute online training course with a multiple-choice assessment offered to all new starters in universities across the UK which embrace equality, diversity and inclusion. Unconscious bias training demonstrates universities' good faith and willingness to address racism and offers a re-take should participants fail the first time. No-one is left behind or outside the unconscious bias community because it is regarded as the principal vehicle for institutional culture change. Participants pass the training course if they learn the language, acceptable behaviours and moral psychology of unconscious bias, if they learn to be able to recognize when it is appropriate to assert that an event is the result of unconscious bias. Such events can range from issues of strategic direction, recruitment and selection, promotion processes, curriculum, admissions as well as student experience and outcomes, for example. Unconscious bias pervades all aspects of institutional life.

Jennifer Saul's (2013:40) work on implicit bias and stereotype threat and their impact on women in Philosophy states that 'implicit biases ... are unconscious biases that affect the way we perceive, evaluate or interact with people from the groups that our biases target'. Further: 
psychological research over the last decades has shown that most people- even those who explicitly and sincerely avow egalitarian views-hold .... implicit biases against such groups as blacks, women, gay people and so on. This is even true of the targeted group. So ... women can be biased against women (Saul, 2013:40).

The Equality Challenge Unit (ECU) has entered the discussion on unconscious bias in academia. The ECU is a registered charity in the UK funded by the Scottish Funding Council, HEFC for Wales, Universities UK and from subscriptions from universities in England and Northern Ireland. Its mission is providing support for 'equality and diversity for staff and students in higher education institutions... [It provides] a central resource and advice to the sector'(https://www.ecu.ac.uk/about-us/ accessed 15/12/2017). The ECU's report on Unconscious Bias and Higher Education (2013) uses a similar definition to Saul's:

Unconscious bias is a term used to describe the associations that we hold which, despite being outside our conscious awareness, can have a significant influence on our attitudes and behaviour. Regardless of how fair minded we believe ourselves to be, most people have some degree of unconscious bias. This means that we automatically respond to others (e.g. people from different racial or ethnic groups) in positive or negative ways. These associations are difficult to override, regardless of whether we recognise them to be wrong, because they are deeply ingrained into our thinking and emotions (http://www.ecu.ac.uk/publications/unconscious-bias-in-highereducation/ accessed 15/9/2017)

Thus, 'unconscious bias happens by our brains making incredibly quick judgements and assessments of people and situations without us realising. Our biases are influenced by our background, cultural environment and personal experiences. We may not even be aware of these views and opinions, or be aware of their full impact and implications' (www.ecu.ac.uk/guidance-resources/employment-and-careers/staff- 
recruitment/unconscious-bias/ accessed 4.5.2017). The ECU has also developed training materials to help us to uncover unconscious bias and act to counter it. However, if they are deeply ingrained into our thinking and emotions they must be resistant to change. Notwithstanding this, unconscious bias has initiated a resurgence in diversity training within a background of continuing racism, sexism, homophobia, ableism, transphobia, class discrimination and rampant cis-gender politics within UK universities. The concern in this article will be to unravel the continued workings of anti-Black and people of colour racism and white supremacy within 'unconscious bias' as an equality, diversity and inclusion mantra within the UK HEl context. Viewing unconscious bias as one aspect of the institutionalization of racial liberalism (Mills, 2017), the analysis will show that unconscious bias is a technology of racialized governmentality which keeps the status quo of whiteliness in place within the libidinal economy of racism. This is all the more pernicious because whiteliness continues to be enabled within universities which claim to be 'post-racial' (Goldberg, 2015) spaces. This article will begin by framing unconscious bias within its social psychological roots which becomes expressed within equality, diversity and inclusion training. It then argues that unconscious bias is an alibi to diminish the recognition, analysis and salience of white supremacy in order to maintain it. This alibi is a wilful silencing which as a political act maintains white innocence at the same time as it enables a white 'will to forget' anti-Black and people of colour racism. The final part of the argument will be focused on the question of who gains from clinging to the idea of 'unconscious bias' as something that can't be helped. This will be done by decolonizing 'white fragility' and the 'self-forgiveness' which 'unconscious bias' installs as the institutional approach to anti-racism until 'we all know better'. Let us now move to thinking about unconscious bias and maintaining whiteliness through ignorance.

\section{Framing unconscious bias in equality, diversity and inclusion training}

Let us pause for a moment and dwell on 'un', the prefix in 'unconscious'. 'Un' is significant because this is where the denial of anti-Black and people of colour racism is maintained. 'Un' denotes an absence of a quality or state, a reverse of, a lack of and gives a negative force to 
conscious bias. It denies the possibility of racist bias and erases the possibility of racism. In contradistinction to this, we have another inscription of 'unconscious bias' which becomes (un)conscious bias to point to its very conscious basis and the fact that 'un' as prefix is an alibi for continuing white supremacy.

Notwithstanding this critique, the making of unconscious bias into a magic bullet means that there is no shortage of research on unconscious bias. For example, Wood et al (2009) found that applicants with British sounding names were more often shortlisted for jobs; Steinpreis et al (1999) discovered both male and female psychologists were more likely to employ male early career researchers; McConnell and Leibold (2001) found research participants exhibited more defensive body language with black researchers than white researchers; Green et al (2007) found doctors were more likely to prescribe effective drugs to white rather than black patients. A survey of the literature on unconscious bias reveals that in the vast majority of cases, proceeding from a social psychological perspective, organizational approaches to unconscious bias begin with the idea that bias is inevitable, that it is ingrained within us within the flight-or-flight response, our unconscious "danger detector" that determines whether or not something or someone is safe before we can even begin to consciously make a determination' (Easterly and Ricard, 2011). From this social psychological perspective which prevails within the equality, diversity and inclusion mission statements of most institutions, the elimination of bias is articulated as an impossibility, inscribed as it is at the 'genetic' and 'instinctual' levels. Racism and ethnocentrism also fall within the inscriptive hard-wiring of bias as, 'ethnic and racial stereotypes are learned as part of normal socialisation and consistent among many populations across time' (Moule, 2011).

For social psychologists (and Equality, Diversity and Inclusion training designers and administrators), not only is unconscious bias inevitable at the individual level. It is inevitable and, indeed, normal at the societal level. Racism - a word rarely used in the unconscious bias semantic field, which is revealing in itself- is therefore not an active choice. Instead, it is part 
of being human, an inescapable product of being a member of society. This approach offers a solution to the organizational cognitive dissonance created by a lack of diversity by removing it from being an active choice to representing it as one over which the individual has no power. Racism from this perspective becomes 'aversive' (Dovidio and Gaertner, 1991), a means of characterizing the 'racial attitudes of many Whites who endorse egalitarian values, who regard themselves as non-prejudiced, but who discriminate in subtle, rationalizable ways' (Dovidio et al, 1997). In aversively racist organizations - like universities - built on foundations of equality, overt forms of racism are often said to have been eliminated. Other forms, aversive forms, can be explained as the product of inevitable, unconscious bias.

Indeed, most unconscious bias training begins from this basis of inevitability and normality, that prejudice is intrinsically within us and here is its first inherent weakness. As well as being a weakness it is also a problematic barrier for much needed anti-racist institutional transformation. An example will suffice here by way of illustration. Duiguid and Thomas-Hunt (2015) conducted an experiment with managers in which they told one group that stereotypes are rare and told the other group that stereotypes were common. Both groups were then given a job interview transcript where candidates asked for more money and were described as either male or female. The group that were told that stereotypes are common were found to be $28 \%$ less likely to hire the female candidate and judged her as $27 \%$ less likable. The findings suggest that when unconscious bias and its inherent stereotyping is normalized, the normalization process may exacerbate discrimination rather than challenging it: if everyone is biased, it's okay if I am too. In a follow-up experiment, Duguid and Thomas-Hunt (ibid) changed tack. Instead of just informing managers that stereotypes are common, they added that the majority of people 'try to overcome their stereotypic preconceptions'. The difference in result was stark as discrimination was eliminated. The managers in the experiment were $28 \%$ more interested in hiring the female candidate and judged her as $25 \%$ more likeable. The implication is clear. To overcome bias, an awareness of normalization is insufficient; instead, what is needed is a more active process. 
The task for those engaged in the equality, diversity and inclusion mission is not just to make individuals aware of their inevitable and 'normal' bias in the belief that such awareness will alchemically reduce racism. The task moves past an awareness of our unconscious bias, to a requirement that we move beyond our 'instinctual nature' and base our judgements and actions on a rational basis. As Easterley and Ricard (2011) argue, most human decisions are made emotionally, and subsequently we collect or generate the facts to justify them. The aim of unconscious bias training is therefore to address the 'dual attitudes' (Wilson, Lindsey and Schooler, 2000) which govern our actions and behaviours. First, the implicit attitudes that 'are automatically activated by the mere presence (actual symbolic) of the attitude object and commonly function without a person's full awareness or control' (Dovidio, Kawakami and Gaertner, 2002). Second, there are the explicit attitudes which 'shape deliberative, wellconsidered responses for which people have the motivation and opportunity to weigh the costs and benefits of various courses of action' (ibid). Successfully overcoming unconscious bias is therefore a matter of individuals ensuring their explicit attitudes are sufficiently free of bias so that they can overcome their inevitably biased implicit attitudes. For Dovidio, Kawakami and Gaerter (2002), this can only be accomplished when individuals have the opportunity and motivation to assess the consequences of their actions. With these two factors - opportunity and motivation - the assumption is that rational, egalitarian, bias-free, explicit attitudes will be allowed to prevail. This is the basis and outcome of unconscious bias training within the academy where the massive under-representation of Black academics and academics of colour is seen as a result of individuals succumbing to inevitable and normalized bias. It is this focus that highlights the inherent weakness of contemporary approaches: the foregrounding of the individual that ignores the institutional and the systemic and positions unconscious bias as an enabler of whiteliness through assertions of ignorance.

\section{Unconscious bias and maintaining whiteliness through ignorance}


Yancy (2015) describes whiteliness as a social, psychological and phenomenological racial reality for white people constructed by an intersubjective matrix whereby white people enact a common being-raced-in-the world which is seen as utterly benign in its naturalness, but which is 'nefariously oppressive'. Thus, we cannot only label acts committed by openly selfascribed racists as racist because racism is not just about believing in the existence of biological 'races' (Yancy, 2015). Getting people racialized as white to let go of such a false ontology, or to understand that racism is immoral, has been shown not to ring the death-knell for anti-Black and people of colour racism. The coloniality of white power keeps being recentred because there is no interrogation of whiteliness, of its political, economic, social, imaginative, epistemic and affective boundaries. This is even the case in contexts in which we are asked to look at our unconscious biases. The problem is that such asking does not commit us to de-legitimizing those white normative practices, systems of thought and affective regimes that maintain and recycle anti-Black and people of colour racism. Part of what keeps whiteliness in place as legitimate is the 'epistemologies of ignorance' of racism (Mills,1997) where racism and white supremacy do not exist or, in a spectacular denial of white supremacy, if racism exists then Black people can be racist too. Drawing from Charles Mills (1997), Sullivan and Tuana (2007:2) assert that racism's epistemologies of ignorance entail that the anti-racist task remains:

[...] tracing what is not known and the politics of such ignorance should be a key element of epistemological and social and political analyses, for it has the potential to reveal the role of power in the construction of what is known and provide a lens for the political values at work in our knowledge practices. [...] [We should pay attention to] the epistemically complex processes of the production and maintenance of ignorance.

We start here thinking about the interweaving of power and a knowing racist ignorance precisely because it enables us to notice that (un)conscious bias is linked to power. As such, (un)conscious bias is also part of the epistemic processes of the production of white 
supremacy and its concomitant 'white fragility' through its claim to ignorance. Robin DiAngelo (2011:54) asserts that:

White people in North America live in a social environment that protects and insulates them from race-based stress. This insulated environment of racial protection builds white expectations for racial comfort while at the same time lowering the ability to tolerate racial stress, leading to what I refer to as White Fragility. White Fragility is a state in which even a minimum amount of racial stress becomes intolerable triggering a range of defensive moves. These moves include the outward display of emotions such as anger, fear, guilt and behaviors such as argumentation, silence, and leaving the stress-inducing situation. These behaviors, in turn, function to reinstate white racial equilibrium.

The institutionalization of unconscious bias as alibi for white supremacy is part of white fragility and, thereby, unconscious bias reinstates white racial equilibrium. The inevitability of (un)conscious bias, the very notion providing palatability to discussions of racial discrimination within organizations, facilitates this ignorance. A discussion of anti-Black and people of colour racism is rarely held in majority-white institutions as claiming to be (un)aware of racism would be exposed as not being about a lack of knowledge or information but rather as ignoring racism, a wilful and intentional turning away from what whiteliness has produced. This wilful ignoring is reflected in the way, for example, discussions around the under-attainment of Black students and students of colour become focused on their deficit in the form of an interrogation of whether they are 'commuting students' or disproportionately working alongside full-time study. This is how universities continue to maintain a claim to ignorance of how they continue to fail students because of racism. It simply becomes the fault of students themselves. Similarly, discussions around the curriculum argue for the seminal nature of white, male, western texts that couldn't possibly be replaced, whilst data showing that Black applicants and applicants of colour receive fewer offers of a place than white students provoke further analysis of the impact of socio-economic status instead of race and racism. In this emergence of racism's denial, the inevitability of (un)conscious bias provides the citational context of 
equality, diversity and inclusion, a performative act that professes an organizational will to challenge racism yet simultaneously avoids engagement with racism via the emphasis on inevitability and normalization.

(Un)conscious bias in institutional contexts diverts our attention from white power, societies structured through racial dominance and the coloniality of power, being, knowledge and affect (Tate and Bagguley, 2017) which it drags into the $21^{\text {st }}$ century. Much like epistemologies of ignorance, the continuous production and tenacious fixation on and maintenance of unconscious bias as part of equality, diversity and inclusion, mean that we go from institutional to personal knowledge, focusing on individual practices rather than ideological values and their imbrication with white institutional power.

The ECU (2013) report asserts that there is a business case for dealing with unconscious bias as well as a moral responsibility on the part of both individuals and institutions to deal with an issue that so pervades every aspect of their/its work:

People and institutions not only have a moral responsibility for their implicit biases, but a business responsibility; institutions need to be efficient and effective, and decisions and actions need to be taken based on evidence and fact, rather than stereotypes and hunches. [...] implicit bias is likely to be relevant to many areas of an institution's work, for example appraisals and grievances, Research Excellence Framework submissions, student admissions and course evaluations [... and] recruitment and selection (http://www.ecu.ac.uk/publications/unconscious-bias-in-higher-education/ accessed 15/9/2017).

Read from an institutional racism perspective this statement is what Ahmed (2004) would call a 'declaration of whiteness' in which 'admissions' of 'bad practice' become signs of 'good practice'. This declaration of whiteness could be called an 'unhappy performative' because by its own admission 'the conditions are not in place that would allow such declarations to do 
what they say' (Ahmed, 2004). The conditions are not in place because (un)conscious bias as an alibi for anti-Black and people of colour racism textures the (im)possibility of their emergence.

(Un)conscious bias (also called implicit bias in the ECU report) impacts all aspects of academic life and remains impervious to remedy because of the affects (called emotions by the ECU above) attached to anti- Black and people of colour 'stereotypes and hunches' which pervade the very walls of the institution as well as dynamize its culture, processes, ideologies and actions. For our purposes here we can say that there is a 'libidinal economy' (Wilderson, 2010) of racism attached to unconscious bias in place in UK HEls.

Wilderson (2010:7) sets out the operation of libidinal economy as related to both affiliation and phobia which he claims is as objective as political economy. As we have seen above in the ECU quote, affiliation and phobia impact political economy as well. Libidinal economy structures psychic and emotional life and as such is resistant to change as, indeed, would be (un)conscious bias because:

libidinal economy functions variously across scales and is as 'objective' as political economy. It is linked not only to forms of attraction, affection, and alliance, but also to aggression, destruction and the violence of lethal consumption... it is the whole structure of psychic and emotional life... something more than but inclusive of or traversed by ... a 'structure of feeling'; it is a dispensation of energies, concerns, points of attention, anxieties, pleasures, appetites, revulsions, phobias capable of great mobility and tenacious fixation (Wilderson, 2010:7).

This 'dispensation of energies, concerns, points of attention, anxieties, pleasures, appetites, revulsions, phobias', underlies the construction of (un)conscious bias as a tool for the erasure of anti-Black and people of colour racism. We can see this tenacious but mobile fixation of 
anti- Black and people of colour racism if we look at how it impacts employment and promotion within UK HEls.

The political economy of anti-Black and people of colour racism and 'misogynoir' in these contexts is reproduced in UK academic institutions as illustrated by employment statistics. The term 'misogynoir' was coined by Moya Bailey in 2010 to describe Black African descent women's specific experiences of sexism and racism and is reflected in the following employment statistics (https://mic.com/articles/152965/meet-moya-bailey-the-black-womanwho-created-the-term-misogynoir\#.Bylkkdja2 accessed 21/12/2016). According to the Higher Education Statistics Agency database for 2013/14 the total number of UK academics in $2013 / 14$ was 194,240 . Of these, 153,675 academics are white, that is, $79.1 \%$ of all academics with only $1.48 \%$ of Black academics. At professor level $83.5 \%$ are white and $0.50 \%$ are Black. Gender negatively impacts Black women's promotion prospects once in academia as there were 60 male Black African professors and 5 female Black African professors, 15 male Black Caribbean professors and 10 female Black Caribbean professors and 5 male Black Other professors and 5 female Black Other professors. This is how 'stereotypes and hunches' act to hinder progress on racial equality through their tenacious attachment to what the Black (wo)man is and can become.

These 'stereotypes and hunches' that are the manifestations of (un)conscious bias come out of 'racializing assemblages' (Weheliye, 2010) in which the Black (wo)man's and (wo)man of colour's bodies emerge out of the 'complex social and historical interstices of whites' efforts at self-construction through complex acts of erasure vis-à-vis Black people [people of colour]. These acts of self-construction, however, are myths/ideological constructions predicated upon maintaining white power' (Yancy, 2005:216). The Black and (wo)man of colour's material, epistemological, social and political body is erased so that white power and privilege can be maintained. Erasure occurs through a peculiar kind of social recognition that distorts reality such that white people mis-see themselves as 'civilized superiors' and non-whites as 'inferior 
savages' whilst producing a 'collective amnesia' about the past of Empire, colonialism and enslavement (Mills 2007).

Such mis-seeing and peculiar social recognition implicates (un)conscious bias as a part of the maintenance of such power, especially if we think through the lens afforded us by the Racial Contract and its epistemologies of ignorance (Mills, 1997). Mills' (1997) Racial Contract inserts an analysis of the operation of white supremacy within the Social Contract invented by Western political philosophers. The Contract and its epistemologies enable white supremacy and its racial entitlements to remain unseen by those racialized as white (Mills, 1997;2007) through incantations of unconscious bias. (Un)conscious bias enables a continuation of white privilege and power as those racialized as white and non-whites who have been co-opted continue to benefit from the world which they have created and maintain where:

Both globally and within particular nations, then, white people, Europeans and their descendants, continue to benefit from the Racial Contract, which creates a world in their cultural image, political states differentially favouring their interests, an economy structured around the racial exploitation of others, and a moral psychology (not just in whites, sometimes in nonwhites also) skewed consciously and unconsciously toward privileging them, taking the status quo of differential racial entitlement as normatively legitimate, and not to be investigated further (Mills, 1997:40).

Mills' (1997) Racial Contract extends from culture, to politics, to economy, to moral psychology which is 'skewed consciously and unconsciously' towards white supremacy, and 'a differential racial entitlement'- white privilege- which is simply taken as a given. If we say that a world is made in which both those racialized as Black/ people of colour and white see white privilege as 'normatively legitimate' then this means that (un)conscious bias relates to norms. Norms are not racism neutral but drag the coloniality of white power (Quijano, 2000; Gutiérrez Rodríguez, 2016) into universities, impacting epistemology, institutional hierarchies and ideas 
about who counts as human which begin from whiteliness as the norm (Wynter, 2003). Norms as expressed through institutional culture, practices like recruitment and selection and processes like curriculum construction are not unconscious but maintain the privilege of those racialized as white and non-whites who support whiteliness (Mills, 1997, 2017; Yancy, 2008; 2012). Black and people of colour phobia lives on within the libidinal economies of white institutions organized by trajectories of repulsion rather than attraction, by phobic strivings "away from" rather than philic strivings "toward" (Ngai, 2005:11). This is the normative antiBlack and people of colour life of universities which is relevant for assertions of (un)conscious bias in equality, diversity and inclusion environments. As phobic opinions and attitudes which it is said that 'we are not aware' that we hold but which influence our actions, (un)conscious bias seems to be one aspect of the epistemologies of ignorance which are part of the Racial Contract instantiated by whiteliness (Mills, 1997). To put it otherwise, (un)conscious bias is part of the apparatus of maintaining white racialized power by calling on the idea of ignorance, of not knowing that what is being done or said is racist because it was not wilfully said or done to hurt, to discriminate, to be racist. It came from somewhere over which we have no control - i.e. the unconscious.

Equality, diversity and inclusion policies are a normative expectation of $21^{\text {st }}$ century UK higher education institutions. However, this normative expectation erases anti- Black and people of colour racism and silences their daily experiences of racist, sexist, ablest, classist, ageist, transphobic and homophobic exclusion, harassment, bullying and discrimination. This erasure is enabled by the increasingly prevalent institutional norm of relating discriminatory institutional culture and individual acts to unconscious bias which we can be trained to 'unlearn'. This 'unlearning' has itself become a normative expectation in which 'confession' is necessary for anti-racist progress to be made institutionally. However, as Dovidio, Kawakami and Gaertner (2002) argue, overcoming the impacts of unconscious bias depends on two elements. First, there must be opportunity, the time to reflect rationally on our implicit attitudes, the space to interrogate our automated responses. The second element - and the one that is most crucial 
- is motivation: implicit attitudes are more prevalent and more powerful when the motivation to address them is absent. Yet the challenging of (un)conscious bias by white institutions and white individuals would require challenging the Racial Contract itself, it would require an acknowledgement of participation within systems of racism that privilege whiteliness. Actually overcoming (un)conscious bias, then, requires a motivation to challenge the very system which has provided white privilege, a motivation that, intrinsically, puts the continuing benefits of white privilege at risk. Here is where the project of overcoming (un)conscious bias threatens to move beyond palatability and challenge the Racial Contract. Consequently, here is where the potential of unconscious bias training within universities breaks down, risking as it does the benefits to whiteliness that continuation of the Racial Contract offers. Here it is then where 'white fragility' and self-forgiveness emerge as key discourses focused on minimizing risk to these benefits while keeping institutional racism in place.

\section{Decolonizing 'white fragility': Self-forgiveness as an approach to institutional racism}

Let us change tack a little and look to another meaning of bias. That is, 'a direction diagonal to the weave of the fabric'. It is taking this diagonal approach to thinking which we will try to establish as we look at the 'white fragility' which is linked to unconscious bias and its attached self-forgiveness as an antidote to institutional racism. In equality, diversity and inclusion understandings, we have to confess to unconscious bias to move towards diminishing institutional racism. This confession instantiates 'a fantasy of transcendence in which "what" is transcended is the very "thing" admitted to in the declaration' (Ahmed, 2004).

What Ahmed speaks about here are very unreflective confessions of doing wrong which will not have the effect of diminishing institutional racism. As Saul (2013:55) avers, 'a person should not be blamed for an implicit bias of which they are completely unaware that results solely from the fact that they live in a sexist [racist] culture. Even once they become aware that they have implicit biases, they do not instantly become able to control their biases and so they should not be blamed for them'. Confessions of (un)conscious bias within the context of 
training in equality, diversity and inclusion can (re)centre white supremacy by removing blame and its accompanying shame and guilt which is part of the process of unlearning white supremacy. White fragility emerges as vulnerability, anger, fear, for which the only balm is self-forgiveness because you simply did not actively know; your racism was unconscious after all, unconscious bias begins from the premise of inevitability and normalization. However, self-forgiveness is inactive as an approach to institutional racism because it relies on introspection on the part of the white self and institution which is what Yancy (2015) calls a 'distancing strategy'. (Un)conscious bias is a strategy to distance the white self from the charge of racism and, indeed, that one can be implicated in its perpetuation. (Un)conscious bias does this by occluding the extent of white supremacy and its impact on Black people and people of colour and on white people themselves by focusing on the white suffering that results from 'irrational claims' of anti-Black and people of colour racism. (Un)conscious bias maintains white supremacy and, indeed, its very definition insists that racist culture and environment are crucial to its existence. The need to focus on white suffering, white fragility, to say it is not your fault, produces a paradox at its centre where those racialized as white are victims of the racism from which they benefit.

Let us use an example from the ECU report (2013:6) cited earlier to look further at why confessions of unconscious bias do not lead to diminishing institutional racism. In this report, higher education institutions are asked to consider whether:

shortlisting can be done anonymously. Particularly for professional and support positions, human resources $(\mathrm{HR})$ processes could be adapted to remove information such as name, school, university, all monitoring data, and anything else that is irrelevant to the application. 
Leaving to one side the difficulty of doing this for academic positions because of the publications aspect, what this approach denies is the impact of organizational culture on who is hired once they are in the interview.

The culture of the organization is a zone of 'suturing' (Yancy, 2015) of whiteliness to white power and privilege which is not undone through confessions of unconscious bias. This is so because white supremacy remains stubbornly in place as it is not challenged by the beneficiaries of the Racial Contract who, as we recall from Mills (1997) above, can also include non-whites. Through an engagement with literature and training in unconscious bias, white people and white institutions simply feel that they need do nothing at all apart from to confess to having unconscious bias. Here we have the Racial Contract in action, where white power and white supremacy as the norm do not need to be investigated any further because 'whiteliness is not the problem, racism is, everybody can be racist including Black people and we are not white supremacists or have right wing politics so we can't be racists'. Does this distancing strategy meant to avert the gaze from whiteliness sound familiar? The charge of Black racism does not take into account the systemic nature of racism, empire, colonialism nor the white constructed 'racializing assemblages' (Weheliye, 2010) that ensure white supremacy, for example. To assert that only self-proclaimed white supremacists are racist is to continue to not see one's part in maintaining whiteliness which remains a 'non-knowing ... [which includes] both straightforward racist motivation and more impersonal social-structural causation ... also moral non-knowings, incorrect judgements about the rights and wrongs of moral situations themselves' within which Black people and people of colour can be implicated (Mills, 2017:57). Confessions of unconscious bias seek temporary solace from the charge of 
anti-Black and people of colour racism and its lived experiences. (Un)conscious bias cannot fix institutional racism because racist white relationalities extend from and to the white self through the process of white subject formation that restrict access to understanding the extent of white racism through epistemologies of ignorance. (Un)conscious bias is about protecting whiteliness from its noxious self through ensuring the non-occurrence of normative white disruption. However, it is this normative white disruption that is necessary if we are to get beyond unconscious bias to thinking about how we can dismantle the toxic culture of institutional racism.

To bring about such normative white disruption, what we have to engage in is the other meaning of bias, a thinking diagonally, against the grain in other words, which ruptures white fragility and the culture of thinking 'it's unconscious bias what done it'. This bias, this diagonal thinking is about opening the white self and the non-white co-opted self to the alterity that it has itself created, to that epistemology which is not seen as knowledge, that morality which is seen as immoral, those affects which are seen as irrelevant for institutional life. Thinking diagonally means, to paraphrase Yancy (2013), that we choose to lose our way, we practice becoming unsutured to whiteliness and we seek to not see it as the normative expectation. From this space of criticality, this bias, we can come to terms with the fact of whiteliness and our complicity with and involvement in maintaining a white 'racist second skin' (Tate, 2018) which extends from the individual to the social and back again in a feedback loop. It is this white racist second skin which remains intact and that needs to be dismantled as it underlies the white epistemologies of ignorance of/about anti-Black and people of colour racism which are so entrenched. Thinking diagonally instantiates a decentring of whiteliness which does not return it as centre or return to it as fragile or vulnerable but acknowledges it as supremacist, a site of the coloniality of power and a 
location which is inimical to everyone's psychic health, both Black and people of colour and white. It is only through a refusal of this return that such bias can enable a form of thinking which dwells on the question of the uneasy feelings, practices and processes caused by white racism's impacts institutionally and personally rather than eliding them through a focus on unconscious bias. Dwelling on uneasy feelings, practices and processes means that the relationality between the white self and anti-Black and people of colour racism cannot be seen from a distance. Dwelling with unease rather than its elision could enable us to challenge and address racism within 'post-race' contexts where racism is seen as only being committed by white supremacists and members of the far right or alt- right and Black people can be racist too. Equality, diversity and inclusion's unconscious bias denies the need for institutional action because it focuses on the individual, volunteerism and minimizing white fragility. Senior leaders must go beyond unconscious bias, foreground the Racial Contract underlying institutional life and prescribe the necessity for anti-racist change which can only emerge when we see racism and white supremacy as problems.

\section{Conclusion}

In Look A White! George Yancy (2012) reminds us that the white self is a location of opacity in terms of its own racism. (Un)conscious bias keeps people racialized as white and the nonwhite co-opted spoken about by Mills (1997) entombed within white racism. This white racism sets the boundaries of who they are and what they can become as it makes them complicit in its operation because they benefit (Yancy, 2012; Mills, 1997). The ECU (2013) definition with which we started pointed us to the fact that to understand unconscious bias we cannot merely look to the individual psyche but also to our institutions' cultures and practices. We have to continuously look diagonally, from the bias, at that culture for the signs of anti-Black and people of colour racism and think about what this has done to our understandings of ourselves in the world that we inhabit. It is from this bias that anti-racism can begin to reconstruct subjectivities, institutions, epistemologies, discourses on the human and regimes of recognition. 


\section{Bibliography}

Ahmed, S. (2004) "Declarations of whiteness: The non-performativity of anti-racism", Borderlands e-journal, 3 (2)

D’Angelo, R. (2011) 'White fragility'. International Journal of Critical Pedagogy, 3(3), pp.5470

Dovidio, J. F., \& Gaertner, S. L. (1991). "Changes in the nature and expression of racial prejudice". In H. Knopke, J. Norrell, \& R. Rogers (Eds.), Opening doors: An appraisal of race relations in contemporary America (pp. 201-241). Tuscaloosa, AL: Univ. of Alabama Press

Dovidio, J.F., Kawakami, K., Johnson, C., Johnson, B. and Howard, A., 1997. "On the nature of prejudice: Automatic and controlled processes". Journal of experimental social psychology, 33(5), pp.510-540

Dovidio, J.F., Kawakami, K. and Gaertner, S.L., 2002. "Implicit and explicit prejudice and interracial interaction". Journal of personality and social psychology, 82(1), p.62.

Duguid, M.M. and Thomas-Hunt, M.C., 2015. "Condoning stereotyping? How awareness of stereotyping prevalence impacts expression of stereotypes". Journal of Applied Psychology, 100(2), p.343

Easterly, D.M. and Ricard, C.S., 2011. "Conscious Efforts to End Unconscious Bias: Why Women Leave Academic Research". Journal of Research Administration, 42(1), pp.61-73. 
Equality Challenge Unit: Advancing Equality and Diversity in Universities and Colleges (2017) “Unconscious bias”, https://www.ecu.ac.uk/guidance-resources/employment-andcareers/staff-recruitment/unconscious-bias/ accessed online, 1.12.17

Equality Challenge Unit (2013) “Unconscious Bias and Higher Education” (http://www.ecu.ac.uk/publications/unconscious-bias-in-higher-education/ accessed $15 / 9 / 2017$

Goldberg, D.T. (2015) Are We All Postracial Yet? Cambridge: Polity Press

Green, A.R., Carney, D.R., Pallin, D.J., Ngo, L.H., Raymond, K.L., lezzoni, L.I. and Banaji, M.R. (2007) The presence of implicit bias in physicians and its prediction of thrombolysis decisions for black and white patients. Journal of General Internal Medicine 22: 1231-1238

Gutiérrez Rodríguez, E. (2016) “Sensing dispossession: Women and Gender Studies between institutional racism and migration control policies in neo-liberal universities", Women's Studies International Forum, 54:167-177

McConnell A.R. and Liebold, J.M. (2001) Relations among the implicit association test, discriminatory behavior, and explicit measures of racial attitudes. Journal of Experimental Social Psychology, 37: 435-442

Mills, C. (2017) Black Rights/White Wrongs: The Critique of Racial Liberalism. New York: Oxford University Press

Mills, C. (2007) "White ignorance", in Shannon Sullivan and Nancy Tuana (eds) Race and Epistemologies of Ignorance. Albany: State University of New York Press, pp 11-38 
Mills, C. (1997) The Racial Contract. Ithaca: Cornell University Press

Moule, J. (2009) Understanding unconscious bias and unintentional racism. Phi Delta Kappan, 90 (5): 320-326

Ngai, S. (2005) Ugly Feelings. Cambridge: Harvard University Press

Quijano, A. (2000) "Coloniality of Power, Eurocentrism and Latin America", Nepantla: Views from South, 103:533-580

Steinpreis, RE, Anders, K, Ritzke, D (1999) The impact of gender on the review of the curricula vitae of job applicants and tenure candidates: a national empirical study. Sex Roles, 41 (7/8): 509-528.

Sullivan, S. and Tuana, N. (2007) "Introduction" in Shannon Sullivan and Nancy Tuana (eds) Race and Epistemologies of Ignorance. Albany: State University of New York Press, pp. 110

Tate, S. A. (2018) The Governmentality of Black Beauty Shame: Discourse, Iconicity and Resistance. London: Palgrave

Tate, S.A. and Bagguley, P. (2017) "Building the anti-racist university: Next steps". Race, Ethnicity and Education, 20 (3): 289-299

Weheliye, A. G. (2014) Habeas Viscus: Racializing Assemblages, Biopolitics and Black Feminist Theories of the Human, Durham: Duke University Press 
Wilderson, F. (2010) Red, White and Black: Cinema and the Structure of US Antagonisms. Durhmam: Duke University Press

Wilson, T.D., Lindsey, S. and Schooler, T.Y. (2000) A model of dual attitudes. Psychological review, 107(1): 101

Wood, M., Hales, J., Purdon, S., Sejersen, T. and Hayllar, O. (2009) A test for racial discrimination in recruitment practice in British cities: research report no 607. London: Department for Work and Pensions

Wynter, Sylvia (2003) "Unsettling the coloniality of being/power/truth/freedom: Towards the human, after Man, its overrepresentation- an argument", CR: The New Centennial Review, 3 (3):257-337

Yancy, G. (2015) Introduction in George Yancy (ed) White Self-Criticality Beyond AntiRacism: How Does It Feel To Be A White Problem. Lanham: Lexington Books

Yancy, G. (2012) Look A White! Philosophical Essays on Whiteness. Philadelphia: Temple University Press

Yancy, G. (2008) Black Bodies White Gazes: The Continuing Significance of Race. Lanham: Rowman and Littlefield

Yancy, George (2005) Whiteness and the return of the Black body. The Journal of Speculative Philosophy, 19 (4): 215-241 